\title{
Organische Chemie.
}

I.

Zusammenselzung einiger organischer. Substanzen,

Von

Du⿴ A s.

(Institut. N. px)

Die Florentinische Veilchenururzel mit Wasser destillirt gab ein perlemutterglänzendes, krystallinisches, blättriges, in Wasser unauflösliches Product, das sich durch Abfiltrirea vom destillirten Wasser gewinnen lässt. Dieses Product enthält:

Kohlenstoff $\mathbf{6 7 , 2}$

Hydrogen 11,5

Sacuerstoff 21,3

Formel: $\mathrm{C}_{8} \quad \mathrm{H}_{\mathrm{8}} \mathrm{O}$.

Diese Formel ist sehr bemerkenswerth. Afan weiss nïmlich, dass das Stearopten des Rosenöls die gleiche Formel hat, wie der Doppelt-Koblenwasssertoff. Die Substanz ats der Veilchenwurzel könnte demnach ein Oxyd der krystallinischen Materie des Rosenöls sein. Die za geringo Menge des Materials verhinderte mich, diess weiter zu untersuchen.

Die Alantucursel (Inula Helenium) enthält ebenfalls ein nüchtiges krystallisirbares Product. Dieses Princip ist bisweilen sogar mit blosem Auge sichtbar und findet sich, in Gestalt kleiner Warzen, im Innern kleiner leicht aufufindender Höhlungen. Man kann es auch durch blose Aullösung in Alkohol oder durch Destillation mit Wasser gewinnen. Ich habe vorzugsweise die auf letzterem Wege gewonnene Substanz untersucht. Sie enthält: 


\section{Dumas, Zusammensetzung organischer Substanzen. 43a}

Kohlenstoff $\mathbf{7 6 , 9}$

Wasserstoff 8,8

Sanerstoff' 14,3

Formel: $\mathrm{C}_{14} \mathrm{H}_{9} \mathbf{0}$.

Der schucar $\approx$ Pfeffer giebt beị der Destillation ein leichtes farbloses Oel, dessen Zusammensetzung ist:

Kohlenstull 87,9

Wasserstoff 11,7

Formel: $\mathbf{C}_{9} \mathbf{H}_{10}$.

Dasselbe stimmt also mit der Zusammenactzung des Terpentinüls überéin.

Der Wachholder giebt gleichfalls ein ätherisches $0 \mathrm{el}$, in welchem ich fand:

Kohlenstoff 87,7

Wasserstoff 11,4

Formel: $\mathrm{C}_{8} \mathrm{H}_{10}$.

Es scheint gleichfalls dem Terpentinäl analog.

Der Sadebaum giebt ein ätherisches Oel, das zwischen 155 bis $161^{\circ}$ kocht und dessen Zusammensetzung ist:

Kohlenstoff 88,6

Wasserstoff 11,6

Formel: $\mathrm{C}_{8} \mathrm{H}_{10}$.

Auch dieses zeigt also Uebereinstimmung mit dem Terpentinộl.

Diese drei Oele können vielleicht ganz einfach isomerisch mit dein Terpentinül sein, ich habe indessen keine Versuche gemacht, um diess zu bestätigen.

Das Cedratöl (l'huile de cédrat) gab mir bei der Analyse:

Kohlenstoff $88, \ldots 5$

Wasserstoff 11, 18

Formel: $\mathrm{C}_{\mathrm{S}} \mathrm{H}_{10^{*}}$

Dieses Oel schien mir dem Citronöl ähnlich, dessen Zusammensetzung ich bekannt gemacht habe.

Das Limettöl (l'huile de limette) gab folgende Zusammensetzung:

Kohlenstoff 87,6

Wasserstolf 11,4.

Formel: $\mathbf{C}_{\mathrm{S}} \mathbf{H}_{10^{\circ}}$

Es scheint also auch mit dem Citronöl übcreinzukommen. 


\section{Dumas, Zusammensetzungorganischer Substanzen.}

Hr. Bonastre hat seit langer Zeit einen Körper aus dem Harze des arbre a Brai (Arbol a Brea) dargestellt, den er mit dem Namen Unterharz des arture $a$ Brai bezcichnet hat. Ich habe verschiedene Proben dieses Körpers analysirt und gefanden :

$$
\begin{aligned}
& \text { Koblegstonf 85,3 } \\
& \text { Wasserstoff 11,7 } \\
& \text { Sauerstolf } \quad 3,0 \\
& \text { Formel: } \mathrm{C}_{72} \mathrm{H}_{60}, \mathrm{O} \text {. }
\end{aligned}
$$

Diese Substanz ist dadurch merkwürdig, dass sie genan die Furmol des Cholestearins besitzt.

\section{II.}

\section{Ueber das Stärkemehl.}

Ueber diesen Gegenstand sind fortgesetzte Untersuchungen von Payen angestelit werden, deren Resultate nach dem Instilut N. 183 folgente sind:

1) Das von allen fremden Körpern befreite stärkemehl bildęt einen unmittelbaren Pflanzenbestandtheil, dessen äussere Schichten mebr Cohürenz zeigen und den verschiedenen Agentien kräftiger widerstehen als die innern, die wahrscheinlich später abgesondert sind. Die äussern, dichten und schwammigen Schichten bilden die ausdehnbaren und zusammenzichbaren Hüllen, welche vermöge dieser Eigenschaft durch Veränderung der Dimensionen die runde Form annehmen könneu.

2) Die Körner derselben Stärkesorte platzen und dehnen sich nach und nach im Wasser bei verschiedenen Temperaturen aus, je nach dem Girade der Cohïsion, den sie nach und nach mit ihrem Alter erlangt haben.

3) Ohne andre Agentien als das Wasser und dic Wärme kann man von der Stärke ein Maximum und ein Mininium von Kleisterconsistenz erhalten in dem Verhältnisse von 150 za 100, eine Beobnchtung die nnmittelbare Anwendung in den Künsten finden kann.

4) Die in der Kälte anaufösliche Anidone in der Stärke, welche, ihrer Unlöslichkeit zu Folge, keine kräftigen Wirkungen 